\title{
ANÁLISIS DEL PROCEDIMIERTO DE LA EXTRADICIÓN DE COLOMBIANOS. CASO FUNDACIÓO POR LA DEFENSA DE LOS COLOMBIANOS PEDIDOS EN EXTRADICIÓn (DECOPEX)
}

\author{
Analysis of the extradition process for \\ Colombians. An insight into the DECOPEX \\ Foundation
}

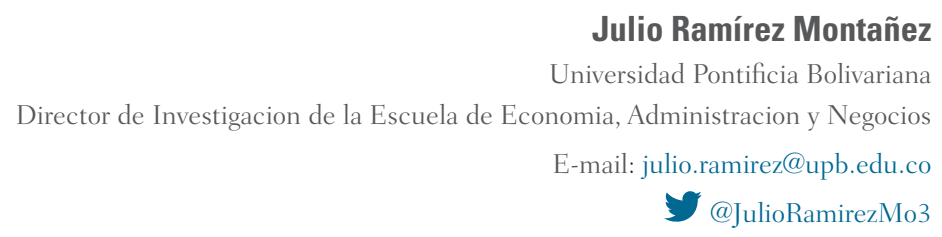

0 Autor

E-mail: julio.ramirez@upb.edu.co

@JulioRamirezMo3

El propósito del presente artículo es exponer una aproximación analítica sobre el trámite de la extradición de colombianos solicitados por Cortes Internacionales de Justicia tomando como referencia la experiencia profesional en la Fundación por la Defensa de los Colombianos Pedidos en Extradición (DECOPEX). Esta organización no gubernamental fue un espacio donde convergieron los familiares de las personas detenidas con solicitud de extradición remitida por algún Estado y que se encontraban recluidos en el pabellón 7 de la penitenciaría de máxima seguridad de Combita. Los propósitos primordiales de DECOPEX estuvieron enfocados en cuatro áreas estratégicas: la defensa de los derechos fundamentales de los reclusos y sus familias; el desarrollo de una estrategia jurídica en el ámbito nacional e internacional; la realización de lobby ante órganos gubernamentales con el fin de reglamentar el procedimiento jurídico de la extradición y la función social ante la problemática de algunas personas que se encontraban detenidas injustamente. 
The purpose of this article is to present an analytical approach on the processing of the extradition of Colombians requested by international courts of justice taking as a reference the personal experience in the Foundation for the Defense of Colombians Orders in Extradition (DECOPEX). This NonGovernmental Organization was a space where converged the relatives of the persons arrested with extradition request from a foreign State mainly and that they were being held in the Pavilion Seven of the Maximum Security Prison of Combita. The primary purposes of DECOPEX were focused on four strategic areas. The defense of the fundamental rights of the inmates and their families; the development of a legal strategy in the national and international level; the realization of lobbying government bodies with the aim of regulating the legal procedure of extradition and the social function before the problem of some people who were wrongfully.

\section{Presentación}

El objetivo del presente artículo es presentar el resultado de un análisis sobre la temática de la extradición de colombianos solicitados por Cortes Internacionales de Justicia tomando como referencia vivencias propias en el marco del proceso de extradición en Colombia bajo la dirección de una organización no gubernamental denominada Fundación por la Defensa de los Colombianos Pedidos en Extradición (DECOPEX). Este documento no pretende presentar ninguna crítica a la extradición ni como instrumento de cooperación internacional, ni como procedimiento administrativo en el territorio nacional, lo que se busca es generar un documento que sirva como fuente de consulta para próximas investigaciones académicas.

Con el fin de cumplir el propósito trazado, en la primera sección del documento se ofrece una visión general de la extradición como instrumento de cooperación jurídica transnacional, presentando un breve análisis conceptual sobre la extradición y sobre los tipos de extradición existentes. En la segunda sección del artículo, se presenta la evolución histórica de la extradición en Colombia, de igual forma se analizan los principios jurídicos que rigen el trámite de la extradición, a continuación se relacionan las fases mediante las cuales se desarrolla el procedimiento en el territorio nacional y las instituciones que hacen parte de este proceso.

La sección final del artículo centra su atención en presentar las vivencias en la experiencia profesional en la dirección de la Fundación DECOPEX donde se buscó proteger el respeto de los derechos fundamentales de las personas solicitadas extradición recluidas en el pabellón 7 de máxima seguridad de la penitenciaría Combita, así como el desarrollo de una estrategia jurídica en el ámbito nacional e internacional que estuvo dirigida a la interposición de las acciones jurídicas del habeas corpus y de la tutela con el fin de buscar que la Corte Suprema de Justicia de Colombia, estudiara jurídicamente cada uno de los casos y no le diera simplemente el trámite administrativo que realiza hasta ahora para su aprobación. Por su parte, la estrategia en el escenario internacional se basó en presentar una demanda ante la Corte Interamericana de Derechos Humanos.

La metodología diseñada para el desarrollo de este documento estuvo dividida en dos fases. La primera de ellas, de carácter experimental, tomando como referencia la experiencia profesional propia en la dirección de DECOPEX, donde hubo un involucramiento con el proceso de cientos de colombianos solicitados en extradición, a los cuales se representó ante organismos gubernamentales velando por sus derechos fundamentales. 
La segunda fase de este documento estuvo enfocada en la recopilación del material escrito en la dirección de la Fundación DECOPEX y en una revisión bibliográfica sobre la temática, con el propósito de plasmarlo en la redacción de un artículo que tuviera una rigurosidad científica en el área de las relaciones internacionales.

\section{El trámite de la extradición en el ámbito internacional}

El trámite de la extradición tiene dos protagonistas principales. El primero de ellos es representado por el Estado requirente, el cual es el que solicita la entrega de un individuo que busca tener en su poder para someterlo a un proceso penal. El segundo protagonista es el Estado requerido que es aquel al que se solicita la entrega de dicho individuo (San Martin, 2014).

La extradición fue concebida como un mecanismo de cooperación internacional para combatir el crimen y erradicar la impunidad; está sometida a un procedimiento especial que concluye con la expedición de un acto administrativo de carácter complejo, pues para su preparación y ejecución concurren varios órganos del Estado pertenecientes tanto a la rama ejecutiva como a la rama judicial del poder público (Sentencia C-243/09, Corte Constitucional).

La extradición se solicita, concede u ofrece de conformidad con los tratados públicos, y a falta de estos se atenderá a lo dispuesto en la ley interna, teniendo esta un carácter supletorio en relación con los tratados de extradición suscritos por los Estados. La extradición es un instrumento de asistencia y solidaridad internacional, generalmente regido por tratados públicos y, en ausencia de estos, por el derecho interno (Sentencia C-243/09, Corte Constitucional).

\subsection{Antecedentes históricos de la extradición}

Según Colín (1993) el primer caso conocido de extradición se remonta a la época antigua y es el ocurrido entre los hititas y Egipto (1271 A. de C.), donde se firmó un tratado de paz entre Hatusie, "Gran jefe de Haittî" y Ramses, gran jefe de Egipto en cuyas cláusulas quedo establecida la extradición, tanto de Egipto como de los hititas (Colín, 1993).

En la Edad Media, la extradición era una forma muy segura de proteger los bienes tanto de los reyes como de los señores feudales, ya que existía un convenio firmado por ellos para procurar el resguardo de sus propiedades. Por medio de este acuerdo se entregaban recíprocamente los enemigos personales que, tratando de huir, se refugiaban en territorio distinto del que podín ser extraditados, ya sea por el rey al señor feudal o viceversa (Pentón, 2014).

En la Edad Moderna, con la Revolución Francesa, se pone en el centro de discusión los derechos del hombre y, por esa vía, en punto al Derecho Internacional y a la extradición -ya con el contenido actual de su término- la necesidad de deslindar la persecución política susceptible del derecho de asilo y la persecución por delincuencia común, propia de la extradición. Ya el convenio de 29 de septiembre de 1765 entre Carlos III de España y Luis XV de Francia, se habla de la entrega de delincuentes comunes por faltas graves, pero siempre sin excluir la entrega por razones políticas (Pentón, 2014).

Pero no es sino hasta el siglo XIX y con el antecedente de la Revolución Francesa y el moderno Estado de derecho que, a partir del Tratado de Paz de Amiens (1803) entre Francia, España 
e Inglaterra, donde claramente se habla de delincuencia común y no se menciona la política y, a partir de la ley interna belga de octubre de 1833, se perfila la estructura formal y material de las leyes de extradición actuales, referidas exclusivamente a la entrega de delincuentes (Pentón, 2014).

Esto quiere decir que la extradición es una institución que tiene un vasto historial de usanza como mecanismo legal que facilita la colaboración judicial entre diversos países. De esta manera, los Estados han solicitado históricamente a individuos que se encuentran en otro territorio con el objetivo de abrir o continuar un procedimiento penal en contra de este.

\subsection{Análisis conceptual de la extradición}

Antes de presentar un estudio de la extradición como figura de cooperación internacional, se hace necesario analizarla haciendo alusión a algunas bases conceptuales fundamentales. Bajo ese entendido, se procederá a mencionar el concepto de extradición y los tipos que se pueden identificar a partir de la práctica de este procedimiento.

Inicialmente se puede señalar que la palabra extradición proviene del griego ex "fuera de" y del latín traditionis, que significa acción de entregar concretamente a una o más personas (Colín, 1993).

En ese mismo sentido, el Diccionario de la Real Academia Española lo define como "el procedimiento por el que las autoridades de un Estado hacen entrega de una persona a la de otro que la reclaman para que pueda ser enjuiciada penalmente este segundo o cumpla en él una pena ya impuesta” (RAE, 2016).

Por su parte, el portal WordReference define la extradición "como la entrega del refugiado o detenido en un país a las autoridades de otro que lo reclaman” (WF, 2016).

En Colombia, en la década de los años ochenta, importantes juristas desarrollaron importantes aportes conceptuales a la extradición como figura jurídica, debido al debate resultado de la implementación de la extradición como lucha contra el narcotráfico. El abogado Carlos Mario Molina Arrubla señala que la institución de la extradición surgió a la luz del derecho internacional público y es un valioso instrumento de batalla que debe ser utilizado por los Estados, en su campaña en contra del crimen, siempre que en tal batalla se enfrenten, de manera aislada, a un enemigo de dimensiones internacionales (Molina, 1980).

Otro aporte importante es realizado por el eminente penalista Alfonso Reyes Echandía, quien señaló en su momento que la extradición es un fenómeno que consiste básicamente en la solicitud, oferta o entrega de un procesado o condenado que un Estado hace a otro para continuar contra él un proceso iniciado o para hacer efectiva en su respecto una sentencia de condena por hecho punible cometido (Reyes, 1970).

Igualmente, Luis Carlos Pérez sostiene que "La extradición es el acto por medio del cual el Estado en cuyo territorio se ha refugiado el responsable de un delito cometido en el extranjero, entrega dicho sujeto al Estado donde ejecutó la infracción o al Estado a que pertenece el infractor" (Pérez, 1984).

Finalmente, es importante destacar que en los últimos años hay un aporte conceptual importante en el año 2008 donde se le da un enfoque al término extradición hacia el campo 
de la cooperación internacional. En ese sentido, la Sentencia C-460 de 2008 de la Corte Constitucional, el magistrado ponente, Nilson Pinilla señala que "la extradición es entendida como un mecanismo de cooperación internacional que busca combatir el crimen y evitar la impunidad" (Sentencia C-460 de 2008).

\subsection{La extradición como instrumento de cooperación jurídica transnacional}

El mecanismo de la extradición es un mecanismo de cooperación judicial internacional que muchos gobiernos alrededor del mundo han adoptado. Se entiende por cooperación judicial internacional la colaboración o asistencia mutua entre Estados, para adelantar diligencias necesarias en el desarrollo de un proceso fuera del territorio del Estado requirente (Ministerio de Relaciones Exteriores de Colombia, 2016).

En materia de cooperación judicial internacional se utilizan como instrumentos internacionales aquellos documentos a través de los cuales deben elevarse las peticiones, para el cumplimiento de las distintas diligencias necesarias dentro de los procesos judiciales o administrativos del caso. Estos pueden ser: exhortos o despachos comisorios, cartas rogatorias o comisiones rogatorias y notas suplicatorias que libran las diferentes autoridades judiciales, sean estas nacionales o extranjeras (Ministerio de Relaciones Exteriores de Colombia, 2016).

El procedimiento de la extradición se encuentra enmarcado dentro del ideal del principio de justicia penal universal, concretado en un reconocimiento mutuo de resoluciones judiciales y respeto absoluto a la interpretación judicial de la normativa interna de cada Estado, donde se vele por el respeto a los derechos fundamentales y a las garantías jurídico-procesales de los procedimientos judiciales de todos los Estados (Calaza, 2015).

En ese sentido, el Comité Internacional de la Cruz Roja (CICR) señala que la obligación de los Estados de cooperar en materia de extradición es inherente a la obligación aut dedere aut judicare del mecanismo de represión que se estipula en los Convenios de Ginebra de 1949 para las "infracciones graves" de estos tratados. El Estado, en cuyo territorio o poder se encuentran las personas acusadas, tiene la posibilidad de juzgarlas o de entregarlas para que las juzgue otra alta parte contratante interesada. Esta posibilidad brinda una oportunidad a dicho Estado para cumplir su obligación de enjuiciamiento o extradición (CICR, 2015).

Esta opción se refrenda en el texto del artículo 88, párrafo 2, del Protocolo adicional I de 1977 a los Convenios de Ginebra, en el cual se estipula explícitamente que, cuando las circunstancias lo permitan, las altas partes contratantes cooperarán en materia de extradición. Este deber supone la obligación de examinar favorablemente cualquier extradición solicitada por un país que justifique su interés jurídico en el enjuiciamiento, si se reúnen los requisitos exigidos por el derecho del Estado requerido (CICR, 2015).

En las últimas dos décadas, la extradición en su acepción más amplia es entendida como un mecanismo de cooperación internacional que busca combatir el crimen y evitar la impunidad. Dicho concepto se concreta en la existencia de un acto formal y solemne por medio del cual un Estado ofrece, concede o solicita la entrega de un sindicado o condenado, nacional o extranjero, a otro Estado, por la presunta comisión de un delito en el territorio del Estado requirente (Calaza \& López, 2014).
El mecanismo de la extradición es un mecanismo de cooperación judicial internacional que muchos gobiernos alrededor del mundo han adoptado 
Lo anterior, con miras a adelantar un proceso en contra de la persona requerida o procurar el cumplimiento de una pena ya impuesta. Sin embargo, es importante precisar que este mecanismo no puede ser equiparado con un proceso penal propiamente dicho y en ese sentido, las autoridades que participan en el trámite para lograr la entrega en extradición de una persona no adelantan un juzgamiento en relación con la inocencia o la culpabilidad de esta respecto del delito por el cual ha sido sindicada o condenada en el Estado solicitante (Calaza \& López, 2014).

La cooperación judicial internacional encuentra su fundamento, de un lado, en la lucha contra el crimen de los Estados que cooperan con la finalidad última de evitar que uno de estos Estados se convierta en un área de impunidad para los delincuentes por el mero hecho de encontrarse en su territorio cuando están acusados por otro Estado y, de otro, en el respeto a los derechos fundamentales y a las garantías jurídico-procesales de cada Estado (Calaza, 2015).

La cooperación judicial internacional requiere de una mayor rapidez en la persecución y el enjuiciamiento de los autores de los delitos tipificados en los textos penales de los distintos cuerpos legislativos internacionales, dificultad esta que se agrava, todavía más si cabe, por la circunstancia del inevitable doble enjuiciamiento al que se ven sometidos quienes, habiendo delinquido en un determinado país, se encuentran, por la circunstancia que sea, en el territorio de otro Estado (Calaza, 2015).

\section{El trámite de la extradición en Colombia}

Desde hace unos años, la figura de la extradición ha enmarcado uno de los procesos más importantes en Colombia en cuanto a la lucha contra diversos delitos tales como el narcotráfico, sin embargo, aún hoy muchos desconocen cómo se lleva a cabo este procedimiento en el territorio colombiano, por ello en esta sección del artículo se presenta la evolución histórica de la extradición en Colombia, de igual forma se analizan los principios jurídicos que rigen el trámite de la extradición, a continuación se relacionan las fases mediante el cual se desarrolla el procedimiento en el territorio nacional y las instituciones que hacen parte de este proceso.

\subsection{Evolución histórica de la extradición en Colombia}

La extradición es un mecanismo de cooperación internacional, y por ende es necesaria la celebración de acuerdos bilaterales para su ejecución o la existencia de normas internas concernientes a dicho procedimiento. Colombia ha celebrado tratados bilaterales de extradición con doce Estados representados en Bélgica, Brasil, Chile, Costa Rica, Cuba, España, Francia, México, Nicaragua, Panamá, Perú, Reino Unido. De igual forma, ha suscrito dos tratados multilaterales representados en el acuerdo sobre extradición, celebrado en Caracas el 18 de julio de 1911 y el convenio sobre extradición celebrado en Montevideo el 26 de diciembre de 1933 (Ministerio de Relaciones Exteriores de Colombia, 2014).

Es importante iniciar señalando que Colombia fue, desde el siglo XIX, uno de los primeros países en suscribir tratados internacionales de lucha contra el crimen, consciente de que el delito tenía que ser atacado más allá de las fronteras patrias y para evitar que nuestro país fuera refugio de delincuentes, según las motivaciones expuestas en esa época.

En el año 1888, Colombia suscribe un tratado multilateral de extradición, donde por primera vez se menciona el tráfico de sustancias controladas como delito causal de extradición y se fija la extradición por vía administrativa como mecanismo aplicable (El Tiempo, 2014).

\section{La cooperación} judicial internacional requiere de una mayor rapidez en la persecución y el enjuiciamiento de los autores de los delitos tipificados en los textos penales de los distintos cuerpos legislativos 
En el siglo XX, en 1936, se introduce en la ley colombiana, por primera vez, el tema de la extradición para actualizar y adecuar lo que ya está en tratados internacionales. La extradición de nacionales se contempla en el Código Penal de ese año (El Tiempo, 2014).

Pero no es hasta el año 1979 cuando el término extradición fue conocido por la mayoría de los colombianos. El entonces embajador de Colombia en Washington, Virgilio Barco Vargas, suscribe el tratado de extradición con Estados Unidos. En este tratado queda establecido que el Gobierno podrá extraditar previo concepto de la Sala Penal de la Corte Suprema de Justicia (El Tiempo, 2014).

La extradición como herramienta de lucha contra el crimen organizado transnacional por parte del gobierno nacional empieza a ser utilizada en firme desde el año 1984, tras el asesinato del ministro de Justicia Rodrigo Lara Bonilla en el norte de Bogotá. Desde esa época empiezan las extradiciones en firme, especialmente hacia Estados Unidos por delitos relacionados al tráfico de drogas y lavado de activos. Es así como el 5 de enero de 1985 son extraditados los primeros cinco colombianos hacia Estados Unidos, entre ellos, el dirigente deportivo Hernán Botero Moreno (El Tiempo, 2014).

El presidente Virgilio Barco en el año 1989, a través de un decreto de estado de sitio, fija la extradición por vía administrativa. Es decir, el Gobierno de manera autónoma asumirá y decidirá sobre los pedidos de extradición hacia Estados Unidos, suspendiendo mientras dure el estado de excepción, las normas del Código Penal y de procedimiento sobre extradición. El decreto que establece la extradición por vía administrativa es expedido el 18 de agosto, coincidiendo con el asesinato de Luis Carlos Galán (El Tiempo, 2014).

En el año 1991 la Asamblea Constituyente, por primera vez en la historia jurídica y política de Colombia, eleva la extradición a rango constitucional y prohíbe la entrega de nacionales. Las extradiciones en trámite son negadas y los presos recobran la libertad. En el año 1997 se restablece la extradición de nacionales mediante una ley aprobada en cuarto debate por la plenaria de la Cámara de Representantes, situación que sigue vigente hasta nuestros días (El Tiempo, 2014).

En la actualidad, el procedimiento de la extradición está reglamentado en el artículo 35 de la Constitución Política de Colombia (art.1 Acto Legislativo 01 de 1997) donde se señala que "La extradición se podrá solicitar conceder u ofrecer de acuerdo con los tratados públicos y, en su defecto, con la ley".

\subsection{Clases de extradición reconocidas por el Gobierno colombiano}

El Ministerio de Relaciones Exteriores de Colombia reconoce seis clases de extradición: extradición activa, extradición pasiva, reextradición, extradición en tránsito, extradición diferida, extradición simplificada. Se explican a continuación:

\section{Cuadro 1. Clases de extradición reconocidas por el Gobierno colombiano}

\begin{tabular}{|l|l|}
\hline Clase de extradición & Definición \\
\hline $\begin{array}{l}\text { Se denomina extradición activa al proceso fundamentalmente jurisdiccional a través del cual se } \\
\text { sustancia la petición que un Estado hace a otro Estado para que una persona le sea entregada, } \\
\text { 1. Exivada de su libertad, con el objeto de ser sometida a proceso o para cumplir una pena privativa } \\
\text { de la libertad ya impuesta por autoridades jurisdiccionales del Estado solicitante (Ministerio de } \\
\text { Relaciones Internacionales de Colombia, 2014). }\end{array}$
\end{tabular}

Colombia fue uno de los primeros países en suscribir tratados internacionales de lucha contra el crimen 


\begin{tabular}{|l|l|}
\hline 2. Extradición pasiva & $\begin{array}{l}\text { La extradición pasiva se refiere a los eventos en que un Estado es requerido, por encontrarse } \\
\text { prófugo en su territorio el acusado o procesado por un delito cometido en otro Estado o con } \\
\text { efectos en este, con miras a su entrega (Ministerio de Relaciones Internacionales de Colombia, } \\
\text { 2014). }\end{array}$ \\
\hline 3. Reextradición & $\begin{array}{l}\text { Esta figura atiende a un mecanismo que tiene lugar cuando el Estado que ha logrado obtener la } \\
\text { extradición de una persona, recibe una nueva solicitud por parte de un tercer Estado, para que } \\
\text { ese mismo sujeto sea enjuiciado u obligado a cumplir una pena en su territorio (Ministerio de } \\
\text { Relaciones Internacionales de Colombia, 2014). }\end{array}$ \\
\hline 4. Extradición en tránsito & $\begin{array}{l}\text { La extradición en tránsito implica una situación en la cual un Estado permite el paso por } \\
\text { su territorio, desde el Estado requerido al Estado requirente, de una persona solicitada en } \\
\text { extradición (Ministerio de Relaciones Internacionales de Colombia, 2014). }\end{array}$ \\
\hline 5. Extradición diferida & $\begin{array}{l}\text { En virtud de lo previsto en el artículo } 504 \text { del Código de Procedimiento Penal, la extradición } \\
\text { diferida se refiere a la facultad de la que dispone el Gobierno Nacional para diferir la entrega de } \\
\text { la persona requerida hasta que sea juzgada y cumpla la pena o hasta que por preclusión de la } \\
\text { instrucción o sentencia absolutoria haya terminado el proceso, en el evento en que el requerido } \\
\text { hubiere delinquido en Colombia (Ministerio de Relaciones Internacionales de Colombia, 2014). }\end{array}$ \\
\hline $\begin{array}{l}\text { La extradición simplificada es un tipo de extradición creada mediante la Ley 1453 de 2011 cuyo } \\
\text { artículo 70, modificatorio del artículo 500 de la Ley 906 de 2004 dispuso lo siguiente: "La persona } \\
\text { requerida en extradición, con la coadyuvancia de su defensor y del Ministerio Público podrá } \\
\text { renunciar al procedimiento previsto en este artículo y solicitar a la Sala de Casación Penal de la } \\
\text { Corte Suprema de Justicia de plano el correspondiente concepto, a lo cual procederá dentro de } \\
\text { los veinte (20) días siguientes si se cumplen los presupuestos para hacerlo [...]" (Ministerio de } \\
\text { Relaciones Internacionales, 2014). }\end{array}$ \\
\hline 6. Extradición simplificadalo
\end{tabular}

Fuente: Ministerio de Relaciones Internacionales de Colombia, 2014. Elaboración propia

Estas clases de extradición deben estar enmarcados en unos principios de derecho internacional que se detallan en la siguiente sección.

\subsection{Principios de extradición en Colombia}

De acuerdo con la Cancillería de Colombia y con la Fundación DECOPEX la extradición se encuentra regida por diez principios derivados de las normas internas aplicables y de los tratados de extradición celebrados por el Estado colombiano y que se deben acatar a cabalidad. Asimismo, es importante señalar que estos principios surgen de los compromisos adquiridos internacionalmente por Colombia.

A continuación, en el cuadro número 2 se presentan dichos principios.

\section{Cuadro 2. Principios de extradición en Colombia}

\begin{tabular}{|l|l|}
\hline $\begin{array}{l}\text { 1. Principio de legalidad } \\
\text { 2. Principio de la especialidad }\end{array}$ & $\begin{array}{l}\text { Este principio establece la obligación de consagrar de forma expresa en el derecho } \\
\text { interno de cada Estado o en un tratado, el delito por el cual es solicitada la } \\
\text { extradición. }\end{array}$ \\
\hline $\begin{array}{l}\text { 3. Principio de la jurisdiccionalidad o de } \\
\text { juez natural }\end{array}$ & $\begin{array}{l}\text { El Estado requirente no podrá extender el enjuiciamiento ni la condena a hechos } \\
\text { distintos de los que de manera específica han dado lugar a la extradición. }\end{array}$ \\
\hline $\begin{array}{l}\text { D. Principio de prohibición de doble } \\
\text { incriminación }\end{array}$ & $\begin{array}{l}\text { El delito por el cual se efectúa la solicitud de extradición deberá estar tipificado } \\
\text { tanto en el Estado requirente como en el Estado requerido. }\end{array}$ \\
\hline $\begin{array}{l}\text { 5. Principio de la conmutación o de la } \\
\text { prohibición de la pena capital }\end{array}$ & $\begin{array}{l}\text { En los eventos en que el ordenamiento jurídico del Estado requirente lo autorice a } \\
\text { ejecutar la pena de muerte contra la persona reclamada en extradición, deberán } \\
\text { ofrecerse las suficientes garantías que aseguren su no imposición en el caso } \\
\text { concreto. }\end{array}$ \\
\hline 6. Principio de non bis in idem & $\begin{array}{l}\text { De conformidad con el principio non bis in idem, no se puede juzgar ni tampoco } \\
\text { imponer una pena dos veces a una persona por el mismo hecho. }\end{array}$ \\
\hline 7. Principio de reciprocidad & $\begin{array}{l}\text { La reciprocidad alude de manera esencial a la noción de la "aplicación por la otra } \\
\text { parte". }\end{array}$ \\
\hline
\end{tabular}




\begin{tabular}{|c|c|}
\hline $\begin{array}{l}\text { 8. Proscripción de la entrega por delitos } \\
\text { políticos o de opinión }\end{array}$ & $\begin{array}{l}\text { En virtud de este principio, se prohíbe la extradición por delitos políticos o de } \\
\text { opinión. }\end{array}$ \\
\hline 9. Non refoulement & $\begin{array}{l}\text { En virtud de esta figura los Estados se encuentran en la obligación de no transferir } \\
\text { a un individuo a otro Estado cuando se verifique que dicha acción podría devenir en } \\
\text { un riesgo de exponer al individuo a serias violaciones de sus derechos humanos. }\end{array}$ \\
\hline 10. La obligación de extraditar o juzgar & $\begin{array}{l}\text { La obligación alternativa de los Estados de extraditar o juzgar a los sospechosos de } \\
\text { la comisión de un delito. }\end{array}$ \\
\hline
\end{tabular}

Fuente: Fundación DECOPEX 2010. Elaboración propia

\subsection{Procedimientos en el trámite de la extradición en Colombia}

De acuerdo a la Dirección de Asuntos Jurídicos Internacionales del Ministerio de Relaciones Internacionales, el trámite de extradición en Colombia se desarrolla cumpliendo las siguientes seis fases presentadas en el cuadro que sigue a continuación.

\section{Cuadro 3. Procedimiento de extradición en Colombia}

\begin{tabular}{|c|c|}
\hline Fase & Descripción del procedimiento \\
\hline Fase I & $\begin{array}{l}\text { Mediante nota verbal, las autoridades extranjeras solicitan a las autoridades colombianas que se expida orden de } \\
\text { captura con fines de extradición a efectos de hacer cumplir la orden de arresto proferida por la corte de ese país. }\end{array}$ \\
\hline Fase II & $\begin{array}{l}\text { La Cancillería recibe del Ministerio de Justicia y del Derecho la solicitud de extradición de la persona requerida. } \\
\text { El requerimiento respectivo es efectuado por la autoridad judicial competente, a saber, un juez o un fiscal. }\end{array}$ \\
\hline Fase III & $\begin{array}{l}\text { La autoridad judicial colombiana presenta la solicitud de extradición del procesado o condenado ante el } \\
\text { Ministerio de Justicia y del Derecho. } \\
\text { El Ministerio de Justicia y del Derecho examina la documentación presentada y, de cumplir con los requisitos } \\
\text { legales exigidos, la envía al Ministerio de Relaciones Exteriores, que la cursará a la Representación Diplomática } \\
\text { respectiva. } \\
\text { La Representación Diplomática presenta la documentación al Ministerio de Relaciones Exteriores del Estado } \\
\text { requerido. }\end{array}$ \\
\hline Fase IV & $\begin{array}{l}\text { Si el idioma del Estado requerido no es el castellano, la Cancillería solicitará la traducción de la documentación } \\
\text { al idioma del Estado requerido. }\end{array}$ \\
\hline Fase V & $\begin{array}{l}\text { La Dirección de Asuntos Jurídicos Internacionales de la Cancillería, mediante memorando dirigido a la respectiva } \\
\text { Embajada de Colombia en el exterior, presentará la documentación que soporta la solicitud formal de extradición } \\
\text { o detención preventiva con fines de extradición, ante el Ministerio de Relaciones Exteriores del Estado requerido }\end{array}$ \\
\hline Fase $\mathrm{VI}$ & $\begin{array}{l}\text { La Dirección de Asuntos Jurídicos Internacionales del MRE remite las comunicaciones que se surtan entre la } \\
\text { respectiva embajada de Colombia y el Estado requerido a las autoridades nacionales competentes, a través del } \\
\text { Ministerio de Justicia y del Derecho. }\end{array}$ \\
\hline
\end{tabular}

Fuente: Dirección de Asuntos Jurídicos Internacionales del Ministerio de Relaciones Internacionales 2014. Elaboración propia

Dentro de este proceso intervienen las autoridades colombianas que se presentan en la siguiente sección indicando cuál es su función principal.

\subsection{Autoridades que participan en el trámite de extradición en Colombia}

Son cinco autoridades colombianas sobre los que recae el procedimiento de extradición en Colombia. Estas son la Fiscalía General de la Nación, el Ministerio de Justicia y del Derecho, el Ministerio de Relaciones Exteriores, la Sala de Casación Penal de la Corte Suprema de Justicia y la Procuraduría General de la Nación, cuyas funciones son explicadas en el cuadro número 3. 
Cuadro 4. Funciones de las autoridades en el trámite de extradición en Colombia

\begin{tabular}{|l|l|}
\hline Entidad & Función \\
\hline 1. Fiscalía General de la Nación & $\begin{array}{l}\text { Se encarga de ordenar la captura, cuando sea precedente, de las personas solicitadas } \\
\text { en extradición por el Estado requirente, aunado a esto se suma la labor de poner a } \\
\text { disposición de las autoridades del Estado extranjero a esa persona, después de haberse } \\
\text { surtido el trámite pertinente. }\end{array}$ \\
\hline $\begin{array}{l}\text { 2. Ministerio de Justicia y del } \\
\text { Derecho }\end{array}$ & $\begin{array}{l}\text { Desempeña la labor de determinar, mediante acto administrativo si ofrece o concede } \\
\text { la extradición de una persona requerida por un Estado extranjero. Su función implica } \\
\text { un grado de interacción constante con el Ministerio de Relaciones Exteriores y la Corte } \\
\text { Suprema de Justicia }\end{array}$ \\
\hline $\begin{array}{l}\text { 3. Ministerio de Relaciones } \\
\text { Exteriores }\end{array}$ & $\begin{array}{l}\text { Durante el trámite de formalización del pedido de extradición, corresponderá al } \\
\text { Ministerio de Relaciones Exteriores adelantar la función de legalización de la } \\
\text { documentación cursada por parte del Estado requirente. }\end{array}$ \\
\hline $\begin{array}{l}\text { 4. Corte Suprema de Justicia - } \\
\text { Sala de Casación Penal }\end{array}$ & $\begin{array}{l}\text { La competencia de la Corte Suprema de Justicia comprende la revisión judicial que se } \\
\text { realiza en Colombia del trámite de extradición donde se verifica que el procedimiento no } \\
\text { viole los principios de extradición en Colombia. }\end{array}$ \\
\hline 5. Ministerio Público & $\begin{array}{l}\text { Actúa como garante de los derechos humanos y de los derechos fundamentales de los } \\
\text { solicitados en extradición. }\end{array}$ \\
\hline
\end{tabular}

Fuente: Fundación DECOPEX, 2010. Elaboración propia, 2014

\subsection{Realidad reciente de los colombianos solicitados en extradición}

La realidad reciente de colombianos solicitados en extradición dista mucho de lo que piensa la gran mayoría de colombianos, acostumbrados a relacionar el término "extraditable" con el grupo delincuencial liderado por los miembros del cartel de Medellín en la década de los noventa. El perfil del extraditable de la actualidad va desde pescadores del choco hasta corredores bursátiles con títulos en el extranjero.

En las visitas realizadas cada quince días en el marco de la visita masculina que se llevaba a cabo los sábados a la penitenciaría de máxima seguridad de Combita, se pudo detectar los orígenes de los reclusos solicitados en extradición durante el periodo 2007-2011. Los grupos más sobresalientes provenían de la región del Pacífico colombiano especialmente de Tumaco y Buenaventura, con casi el 35\% de la población penitenciaría a la espera de su extradición, seguido de personas nacidas en la costa atlántica y de San Andrés y Providencia con un 20\% y provenientes del Departamento de Antioquia un 15\% y del Valle del Cauca un 10\% y un 20\% proveniente del resto del país (DECOPEX, 2011). 
Gráfico 1. Principales regiones de origen pabellón 7 penitenciaría Combita

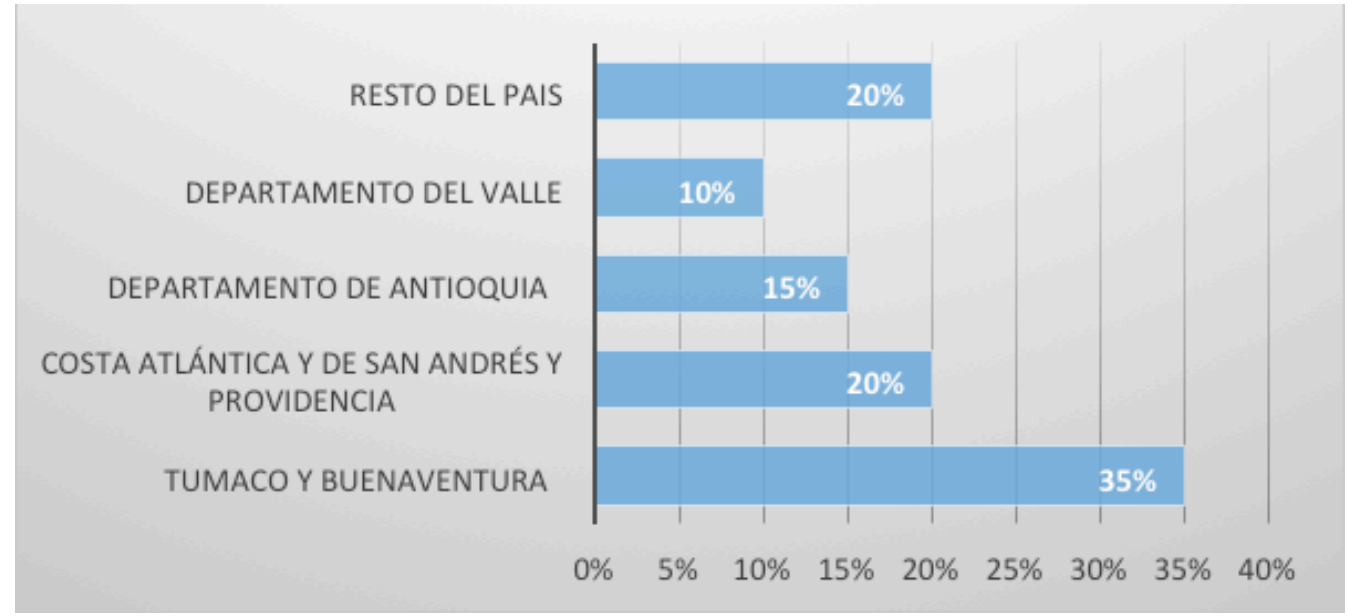

Fuente: DECOPEX. Elaboración propia

En cuanto a las profesiones, la más predominante era la de comerciante independiente con un $45 \%$, seguido por empresarios, con un $20 \%$ y en una menor proporción se encontraban oficiales y suboficiales de las fuerzas militares y de policía, miembros de grupos insurgentes de la FARC y el ELN y personas con profesiones tales como tapiceros, chóferes, recepcionistas, agricultores, jubilados de instituciones bancarias, vendedores ambulantes de plátano, siendo este grupo minoritario por el que trabajaba la Fundación DECOPEX.

Gráfico 2. Principales profesiones de colombianos solicitados en extradición

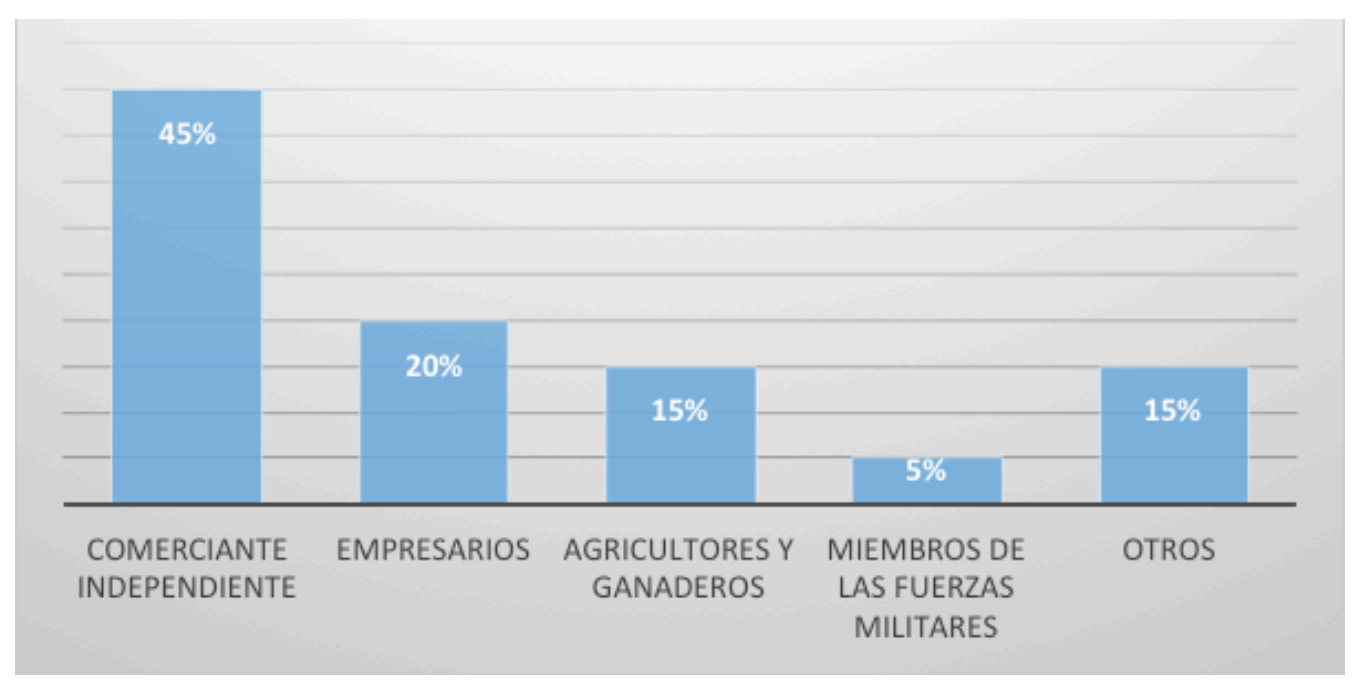

Fuente: DECOPEX. Elaboración propia

Las estadísticas presentadas por el Ministerio de Justicia de Colombia (2012) sobre la evolución de la extradición entre los años 2000 y 2011 señalan que, en este periodo de tiempo, fueron extraditados 1.221 colombianos, siendo el año 2008 en el que se produjeron más extradiciones (207). Los países requirentes con mayor número de solicitudes fueron Estados Unidos, España y Perú. En cuanto a los principales delitos se destaca el narcotráfico 
con un $75 \%$ de los colombianos extraditados seguido por delitos relacionados al narcotráfico con $11 \%$, lavado de activos con $10 \%$, homicidio $2 \%$ y tráfico de migrantes $1 \%$ (Ministerio de Justicia de Colombia, 2012).

Gráfico 3. Principales delitos por solicitudes de extradición 2007-201 1

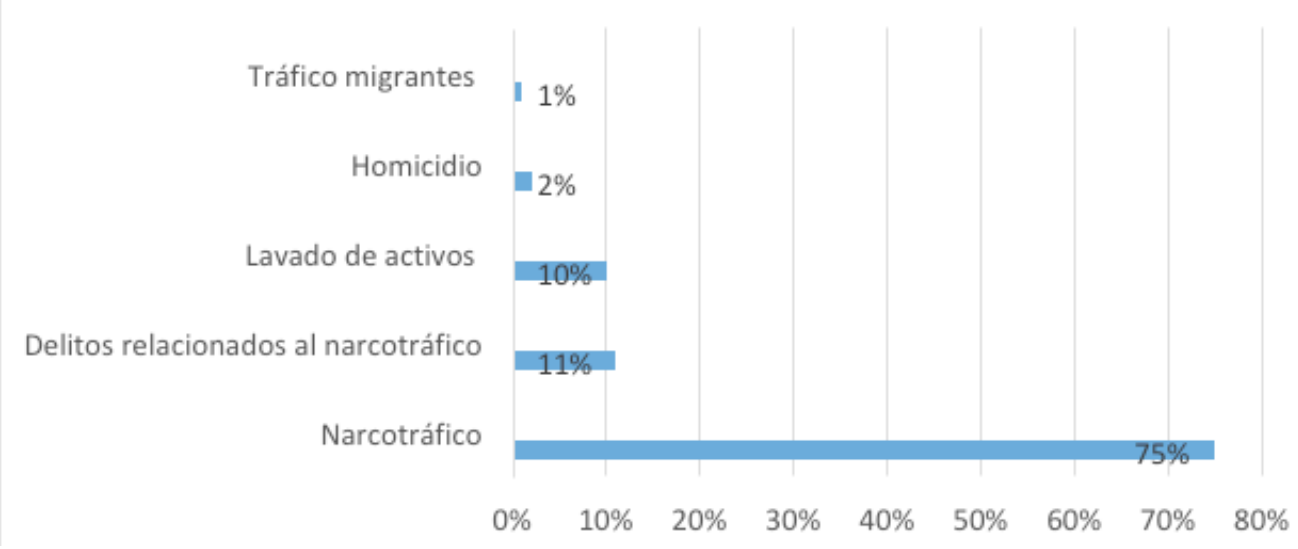

Fuente: DECOPEX. Elaboración propia

A continuación, se presentan algunos aspectos relacionados a la realidad de los colombianos a la espera de su extradición, donde se destacan los que siguen.

\subsubsection{Entrampamiento}

El Diccionario de la Real Academia Española define entrampar como: engañar artificiosamente; enredar, confundir un negocio, de modo que no se pueda aclarar o resolver. Sin embargo, el término entrampamiento en el entorno del trámite de solicitud de extradición se refiere a la etapa realizada por los cuerpos policivos de algunos países, especialmente de Estados Unidos, donde miembros de su policía de inteligencia se infiltran en organizaciones delictivas buscando pruebas de su accionar. El problema de esta etapa es que en ocasiones se presenta lo que en Colombia es conocido como "falsos positivos".

Según estadísticas producidas por la Fundación DECOPEX, las solicitudes de extradición provienen en un 96\% de Cortes Federales de Estados Unidos principalmente por delitos de narcotráfico y lavado de activos. En la mayoría de estos casos el factor común es el denominado entrampamiento. Este entrampamiento es ocasionado por agentes de autoridades policivas de Estados Unidos y Colombia quienes inducen a ciudadanos corrientes a cometer delitos para mostrar resultados en su lucha contra el crimen.

En ese sentido, de acuerdo a una carta abierta de los internos en vía de extradición, patios 12 y 16 de la cárcel La Picota de Bogotá, dirigida a los senadores, representantes, autoridades judiciales de Colombia y ciudadanía en general con fecha del 22 de octubre de 2014, se acusa a las autoridades de crear sofisticados aparatos para inducir al delito, tales como empresas y cárteles. De igual forma, argumentan que la DEA en asociación con autoridades colombianas, monta redes de tráfico de narcóticos y lavado de activos, para los cuales busca perfiles adecuados 
y les propone atractivos negocios que terminan siendo una elaborada telaraña para involucrar inocentes en ilícitos, con los cuales engrosar sus estadísticas "exitosas contra el delito".

En la mayoría de los casos, las pruebas son presentadas en grabaciones telefónicas en un CD que es denominado por las autoridades americanas como discovery. En este CD se presentan las conversaciones intervenidas a los acusados donde se le da una interpretación a la conveniencia de los funcionarios. Por ejemplo, se dieron casos de personas acusadas por una llamada telefónica donde se hace mención a una transacción bancaria por determinado monto de dinero y para las agencias norteamericanas se trataba de una operación de narcotráfico por un monto de droga, es decir interpretan las conversaciones a su acomodo.

\subsubsection{Solicitud para que la extradición sea un procedimiento jurídico y no administrativo}

El procedimiento de extradición de la mayoría de los colombianos requeridos por cortes internacionales tarda entre 12 y 18 meses, a la espera de que se cumpla con el trámite en las diferentes instancias judiciales de Colombia, en la Oficina de Asuntos Internacionales de la Fiscalía General de la Nación, la Corte Suprema de Justicia y el Ministerio de Justicia. Durante este tiempo de espera para su extradición, estos colombianos son recluidos en cárceles de máxima seguridad (Combita y La Picota) donde se ven enfrentados a la rigidez del sistema penitenciario impuesto por el INPEC.

Muchos de estos reclusos reclaman que el papel de la Corte Suprema de Justicia sea más activo en el proceso jurídico analizando cada uno de los casos. Pues los magistrados de esta honorable corte lo único que hacen en el procedimiento es verificar que se cumplan los requisitos de la extradición, sin analizar jurídicamente cada uno de los casos, convirtiéndose en un programa sistemático, que mensualmente extradita entre 15 y 20 colombianos.

\subsubsection{Sistema penitenciario inadecuado}

Los colombianos a la espera de su extradición son enviados a penitenciarías de máxima seguridad donde se ven enfrentados a fenómenos que afectan a toda la población penitenciaría de Colombia como el hacinamiento, la alimentación inadecuada y la constante violación de derechos fundamentales por parte del Instituto Nacional Penitenciario (INPEC) a los internos y a los familiares que realizan semanalmente sus visitas.

Es por ello por lo que muchos colombianos solicitados en extradición prefieren agilizar el proceso en suelo nacional para ser extraditados prontamente, pues saben que en muchos países requirentes gozan de una mejor calidad de vida en el momento de purgar sus penas.

Estas fueron las tres razones fundamentales por las cuales algunas personas afectadas con el proceso de extradición en Colombia por tener familiares y amigos padeciendo este viacrucis decidieron tomar riendas en el asunto y crear una organización no gubernamental que velara por el respeto de estas personas. Parte de la experiencia en la Fundación DECOPEX, se presenta en la siguiente sección como aporte al estudio de esta temática.
El procedimiento de extradición de la mayoría de los colombianos requeridos por cortes internacionales tarda entre 12 y 18 meses, a la espera que se cumpla con el trámite en las diferentes instancias judiciales de Colombia 


\section{Experiencia en la dirección de la Fundación por la Defensa de los Colombianos Pedidos en Extradición (DECOPEX)}

La Fundación DECOPEX fue una organización no gubernamental que funcionó entre los años 2007 y 2010 con sede en Bogotá, que propendía por la defensa de los derechos de los colombianos solicitados en extradición por cortes internacionales y estaba conformada principalmente por familiares de personas que se encontraban recluidas en el pabellón 7 de la penitenciaría de alta seguridad ubicada en el municipio de Combita, Boyacá.

Esta ONG fue presidida por el autor del presente artículo en calidad de gerente y de representante legal, siendo el espacio en el que convergieron los familiares de las personas detenidas con solicitud de extradición por alguna nación extranjera.

Los propósitos primordiales de esta fundación estuvieron enfocados en cuatro áreas estratégicas de gestión. En la primera de ellas se propuso velar por el respeto de los derechos fundamentales de los reclusos y sus familias; en la segunda de ellas, el desarrollo de una estrategia jurídica en el ámbito nacional e internacional. La tercera de ellas, la realización de lobby ante órganos gubernamentales con el fin de reglamentar el procedimiento jurídico de la extradición y la cuarta área de gestión estuvo enfocada a la función social ante la problemática de algunas personas que se encontraban detenidas injustamente. Estas áreas de gestión de la ONG DECOPEX se presentan a continuación.

\subsection{Debate por el respeto de los derechos fundamentales de las personas solicitadas en extradición y de sus familias}

Es importante resaltar que, hasta el año 2012, las personas solicitadas en extradición que se encontraban a la espera de su envío hacia los Estados requirentes eran recluidas en el pabellón de máxima seguridad de la penitenciaría ubicada en el municipio de Combita (Boyacá). Esta penitenciaría se encuentra ubicada a 20 minutos de la ciudad de Tunja, capital del Departamento de Boyacá y es considerada por expertos en seguridad como la más segura de Latinoamérica por su ubicación geográfica y por la avanzada tecnología con la que fue dotada.

A esta cárcel eran enviados los reclusos solicitados en extradición a la espera de la autorización por parte de la Corte Suprema de Justicia, esta prisión cuenta con capacidad para 1.600 reclusos e hizo parte de un convenio entre el Gobierno colombiano y el estadounidense, que buscó cambiar el sistema penitenciario en el país con recursos provenientes del Plan Colombia (INPEC, 2016).

Esta penitenciaría es conocida por la rigurosidad de su sistema de seguridad, al contar con tres anillos de seguridad periférica (policía, ejército, guardia penitenciaría) y en la parte interna cuatro anillos de cerramiento, uno de los cuales está compuesto por sensores que, al detectar a una persona en ese corredor, disparará la alarma y los reflectores (INPEC, 2016).

La Fundación DECOPEX originó un debate con las entidades gubernamentales dentro del Consejo Superior de Criminalística encaminado a mejorar las condiciones de reclusión de los reos en el patio 7 de la cárcel de alta seguridad de Combita debido a problemas de hacinamiento, condiciones de insalubridad, violaciones al debido proceso y el régimen de horarios de visita.

De igual forma, los familiares que realizaban las visitas a las personas recluidas en esta prisión veían como sus derechos fundamentales eran transgredidos por el entorno agreste de las visitas, al
La Fundación DECOPEX fue una organización no gubernamental que funcionó entre los años 2007 y 2010, que propendía por la defensa de los derechos de los colombianos solicitados en extradición por cortes internacionales 
realizar filas de hasta 6 horas en la madrugada a temperaturas bajo cero, recibiendo en ocasiones abusos por parte del personal del Instituto Nacional Penitenciario de Colombia (INPEC).

Los resultados de este debate dentro del Consejo Superior de Criminalística se vieron expresados en una visita realizada a la penitenciaría de Combita por el viceministro de Justicia de la época, Guillermo Francisco Reyes González, el defensor del pueblo de Boyacá Gustavo Adolfo Tobo, el director general del INPEC Eduardo Morales Beltrán y enviados de la Procuraduría General de la Nación, donde se verificaron las condiciones precarias de reclusión dentro de este centro penitenciario.

Como consecuencia de ello, a partir del año 2012 el gobierno nacional tomo la decisión de reubicar a los denominados extraditables en el piso 9 del pabellón de extraditables de la cárcel La Picota, ubicada en la ciudad de Bogotá, haciendo más factible las visitas de los familiares y de los abogados a las personas solicitadas en extradición.

\subsection{El desarrollo de una estrategia jurídica con el fin de interponer recursos judiciales colectivos}

La estrategia desarrollada en el plano jurídico de la Fundación DECOPEX se desarrolló tanto en el plano nacional como internacional interponiendo recursos jurídicos en las cortes nacionales y en la Corte Interamericana de Derechos Humanos.

La estrategia interna llevada a cabo por el equipo jurídico de DECOPEX estuvo dirigida a la interposición de figuras jurídicas tales como el habeas corpus y la tutela con el fin de buscar que la Corte Suprema de Justicia de Colombia, estudiara jurídicamente cada uno de los casos de los colombianos solicitados en extradición y no le diera simplemente el trámite administrativo que realiza hasta ahora para su aprobación.

La estrategia en el escenario internacional se basó en presentar una demanda ante la Corte Interamericana de Derechos Humanos el 26 de octubre del 2007, utilizando como argumento que en el proceso de extradición de colombianos al exterior se presentaba una violación masiva al derecho fundamental del Non bis in idem, porque se juzgaba a las personas solicitadas en extradición dos veces por el mismo hecho, una en Colombia y la otra en el país que realizaba el requerimiento.

\subsection{Realización de lobby ante el Gobierno nacional y el Congreso de la República con el fin de reglamentar el procedimiento jurídico de la extradición}

Es claro que el procedimiento jurídico de la extradición en Colombia se limita al estudio de la Corte Suprema de Justicia del cumplimiento de unos requisitos básicos y su posterior aprobación. Este procedimiento es considerado por algunos juristas como un simple "procedimiento notarial".

Buscando reglamentar el procedimiento jurídico de la extradición, los miembros de la Fundación DECOPEX realizaron actividades de lobby ante algunos honorables senadores y representantes a la Cámara de Colombia. Este lobby se creó con la finalidad de solicitar la convocatoria del Consejo Superior de Criminalística para que se estudiara el procedimiento de la extradición y se reglamentara dicho procedimiento de cooperación internacional por parte del Gobierno
La estrategia desarrollada por la Fundación DECOPEX se desarrolló tanto en el plano nacional como internacional interponiendo recursos jurídicos en las cortes nacionales y en la Corte Interamericana de Derechos Humanos 
colombiano, sin mucho éxito, debido a que el tema de la extradición en Colombia todavía es tema vedado para la opinión pública, que no trae consigo dividendos políticos, sino por el contrario se desconfía de este tema por la creencia que todos los solicitados en extradición son grandes capos del narcotráfico.

\subsection{Función social ante las injusticias que se presentaban con la implementación de este trámite legal}

Existe la creencia popular de que todas las personas solicitadas en extradición son personas muy adineradas por estar involucradas en el narcotráfico o el lavado de activos. Sin embargo, la realidad de algunas personas detenidas en el pabellón 7 de la cárcel de Combita distaba mucho de esta creencia.

En este pabellón convergían personas con profesiones disímiles como tapiceros, agricultores, chóferes, jubilados de entidades bancarias, celadores, que en ocasiones no tenían los recursos económicos para los desplazamientos de sus familiares y el pago de honorarios profesionales de abogados. En ocasiones y gracias a actividades organizadas por los familiares se alcanzó a reunir dinero para ayudar a estas personas.

Otro aspecto en el que se llevó a cabo una labor productiva fue en el campo de la denuncia. Una de las principales críticas realizadas al procedimiento de extradición de colombianos al exterior por parte de la Fundación DECOPEX estaba relacionada a los continuos errores presentados en la identificación de los detenidos por parte de las autoridades colombianas y las del país solicitante.

Dentro del tiempo de gestión de la Fundación DECOPEX se presentaron casos muy sonados en los medios de comunicación sobre personas inocentes que estaban recluidas en espera de su extradición y que con el tiempo se demostró su inocencia, al ser confundidas con otras personas o al darle otra interpretación al sentido de las conversaciones telefónicas.

El caso más representativo fue el de Gabriel Consuegra, el vendedor de plátanos extraditado a los Estados Unidos por error y que fue bautizado por las autoridades con el alias de "El Platanero". Consuegra fue acusado por la justicia norteamericana de ser el titular de varias cuentas bancarias, en diversos países de la cuenca del Caribe, que eran utilizadas para lavar activos procedentes del negocio del narcotráfico. Según el proceso, su hijo, en ese entonces de 23 años y estudiante de enfermería, había participado en el lavado de dólares en Colombia.

El señor Consuegra y su hijo fueron repatriados a Colombia luego de pagar una pena de 3 años sin encontrar cargos en su contra y las únicas pruebas presentadas por el Gobierno de Estados Unidos fueron unas grabaciones telefónicas donde los implicados hablaban de "verdes" al referirse a plátanos verdes pero la interpretación dada por las autoridades policiales de Colombia y Estados Unidos es que se referían a dólares, acusándolos de pertenecer a una estructura de lavado de dinero.

Otro caso fue el del señor Juan Vicente Gómez Castrillón quien fue solicitado por el Tribunal del Distrito de los Estados Unidos para el Distrito Sur de Nueva York y en su descripción física era presentado como "un hombre caucásico" y el señor Gómez es de raza negra. Además de este error, más otros relacionadas con su nombre y su edad, pues el hombre solicitado tenía 48 años mientras que Castrillón estaba próximo a cumplir los 70 años, son pruebas de la fragilidad del sistema de extradición en Colombia.
Dentro del tiempo de gestión de la Fundación DECOPEX se presentaron casos muy sonados sobre personas inocentes que estaban recluidas en espera de su extradición y que con el tiempo se demostró su inocencia 


\section{Conclusiones}

Colombia fue, desde el siglo XIX, uno de los primeros países en suscribir tratados internacionales de lucha contra el crimen, consciente de que el delito tenía que ser atacado más allá de las fronteras patrias y para evitar que nuestro país fuera refugio de delincuentes, según las motivaciones expuestas en esa época.

El procedimiento de la extradición se encuentra enmarcado dentro del ideal del principio de justicia penal universal concretado en un reconocimiento mutuo de resoluciones judiciales y respeto absoluto a la interpretación judicial de la normativa interna de cada Estado donde se vele por el respeto a los derechos fundamentales y a las garantías jurídico-procesales de los procedimientos judiciales de todos los Estados.

En el ámbito jurídico colombiano es definida por la sentencia C-460 de 2008 de la Corte Constitucional de la siguiente forma: "La extradición en su acepción más amplia es entendida como un mecanismo de cooperación internacional que busca combatir el crimen y evitar la impunidad".

La extradición se encuentra regida por diez principios derivados de las normas internas aplicables y de los tratados de extradición celebrados por el Estado colombiano y que se deben acatar a cabalidad. Asimismo, es importante señalar que estos principios surgen de los compromisos adquiridos internacionalmente por Colombia.

El procedimiento de extradición de la mayoría de los colombianos requeridos por cortes internacionales tarda entre 12 y 18 meses a la espera de que se cumpla con el trámite en las diferentes instancias judiciales en Colombia en la Oficina de Asuntos Internacionales de la Fiscalía General de la Nación, la Corte Suprema de Justicia y el Ministerio de Justicia. Durante este tiempo de espera para su extradición, estos colombianos son recluidos en cárceles de máxima seguridad (Combita y La Picota) donde se ven enfrentados a la rigidez del sistema penitenciario impuesto por el INPEC.

Los propósitos primordiales de esta fundación estuvieron enfocados en cuatro áreas estratégicas de gestión. En la primera de ellas se propuso velar por el respeto de los derechos fundamentales de los reclusos y sus familias; en la segunda de ellas, el desarrollo de una estrategia jurídica en el ámbito nacional e internacional; la tercera de ellas, la realización de lobby ante órganos gubernamentales con el fin de reglamentar el procedimiento jurídico de la extradición y la cuarta área de gestión, estuvo enfocada a la función social ante la problemática de algunas personas que se encontraban detenidas injustamente.

Los grupos más sobresalientes de extraditables en el periodo de funcionamiento de la Fundación DECOPEX provenían de la región del Pacífico colombiano especialmente de Tumaco y Buenaventura con casi el 35\% de la población penitenciaría a la espera de su extradición, seguido de nacidos la costa atlántica y de San Andrés y Providencia con un 20\% y provenientes del Departamento de Antioquia un 15\% y del Valle del Cauca un $10 \%$ y un $20 \%$ proveniente del resto del país.
La extradición se encuentra regida por diez principios derivados de las nomas internas aplicables y de los tratados de extradición celebrados por el Estado colombiano y que se deben acatar a cabalidad 


\section{Bibliografía}

Barroso, C. G. (1982). Interpol y el procedimiento de extradición. Madrid: EDERSA.

Calaza, S., y López, R. (2014). Mecanismos judiciales de cooperación internacional versus áreas de impunidad de la delincuencia. Caracas.

Calaza, S., y López, R. (2012). Cooperación judicial internacional extradición y euroorden. Caracas.

Carta abierta de los internos en vía de extradición, patios 12 y 16 de la cárcel La Picota de Bogotá, dirigida a los senadores, representantes, autoridades judiciales de Colombia y ciudadanía en general con fecha del 22 de octubre de 2014.

CICR. (2014). Cooperación en el ámbito de la extradición y de la asistencia mutua judicial en materia penal internacional. Comité Internacional de la Cruz Roja, 1, 88.

Colín Sánchez, G. (1993). Procedimiento para la extradición. México: Ed. Porrúa.

Dirección de asuntos jurídicos internacionales Ministerio de Relaciones Internacionales. (2014). Guía práctica sobre la extradición. Bogotá: Ministerio de Relaciones Internacionales de Colombia.

European Commission - Directorate - General for Justice. (2013). Estudio sobre cooperación jurídica, auxilio judicial internacional y extradición en material de tráfico de drogas y otros delitos relacionados, entre la UE y sus Estados miembro y los países de América Latina y el Caribe. Luxembourg: Publications Office of the European Union.

Guanumen Pacheco, M. (2012). La narcotización de las relaciones Colombia-Estados Unidos. Revista de Relaciones Internacionales, Estrategia y Seguridad, 7(2), 221-244.

Méndez Silva, R. (2000). La firma de los tratados. Cuestiones Constitucionales, julio-diciembre.

Ministerio de Relaciones Exteriores de Colombia. (2014). Tratados bilaterales y regionales. Ministerio de Relaciones Exteriores de Colombia.

Ministerio de Justicia de Colombia. (2012). Evolución de la extradición principales países destino y delitos 2000 y 2011.

Molina Arrubla, C. (1980). Análisis crítico de la ley 27 de 1980: tratado de extradición entre Colombia y Estados Unidos. Revista Facultad de Derecho y Ciencias Políticas Universidad Pontificia Bolivariana, (67), 49-82.

Penton Negrin, A. (2012). Antecedentes históricos de la extradición (Tesis). Universidad Autónoma.

Peña J., R. (1974). La extradición. Revista Chilena de Derecho, 1(3/4), 375-380.

Pérez, L. (1984). Derecho penal: partes general y especial (2 $2^{\mathrm{a}}$ ed.). Bogotá: Ed. Norma.

Ramírez, J. (2010). Informe de Gestión Fundación DECOPEX.

Redacción El tiempo (20 de junio 1997). La historia jurídica de la extradición. El tiempo. Recuperado de http:/www.eltiempo.com/archivo/documento/MAM-597829

Reyes Echandía, A. (1970). Diccionario de Derecho Penal. Bogotá: Universidad del Rosario. 
San Martín, C. (2012). La extradición y la cooperación judicial internacional. Lima: Ed. Pontificia Universidad Católica del Perú.

Sentencia C-460 de 2008. Corte Constitucional. Magistrado Ponente: Dr. Nilson Pinilla Pinilla.

Verduzco, G. R., \& Verduzco, A. A. G. R. (2000). Extradición en derecho internacional aspectos $y$ tendencias relevantes (No. $341.44341 .4 / 88$ ). 